\title{
Transformações na economia internacional, comércio e gênero: um estudo de caso da participação feminina na indústria de vestuário de Bangladesh
}

Patricia Nasser de Carvalho*

Artigo recebido: 23 de abril de 2020

Artigo aprovado: 14 de dezembro de 2020

Doi: https://doi.org/10.12804/revistas.urosario.edu.co/ desafios/a.8968

Para citar este artigo: Carvalho, P. N. (2021). Transformações na economia internacional, comércio e gênero: um estudo de caso da participação feminina na indústria de vestuário de Bangladesh. Desafíos, 33(2), 1-40. https://doi.org/10.12804/revistas.urosario.edu.co/ desafios/a.8968

\section{Resumo}

Partindo da premissa de que os papeis de homens e de mulheres são distintos na economia, e, ao mesmo tempo, são reforçadas por decisões políticas e pela estrutura social, o objetivo deste trabalho é investigar qual foi a participação feminina na indústria de vestuário de Bangladesh para o exitoso desempenho econômico do país da década de 1980 até a atualidade. A partir da aplicaşão de uma perspectiva analítica beterodoxa e de um estudo de caso, demonstra-se que não houve significativo progresso tecnológico, diversificaşão produtiva e desenvolvimento econômico em Bangladesh à altura do ritmo das taxas de crescimento do país. Além disso, o aumento da demanda de mão de obra feminina na indústria de vestuário, um setor-chave da economia, não

* Universidade Federal de Minas Gerais. Correio eletrônico: patricia.nasser.carvalho@ gmail.com.

ORCID: http://orcid.org/0000-0002-8152-9779 
retirou as mulheres da condição de dependência ou subordinação em relação aos homens, uma vez que persistem desigualdades de gênero no mercado de trabalho do país. Palavras-chave: gênero; comércio; vestuário; Bangladesh; desigualdade.

\title{
Transformaciones en la economía internacional, comercio y género: un estudio de caso sobre la participación femenina en la industria de la confección de Bangladesh
}

\begin{abstract}
Resumen
Basado en la premisa de que los roles de hombres y mujeres son distintos en la economía y, al mismo tiempo, se ven reforzados por decisiones politicas y por la estructura social, el objetivo de este trabajo es investigar cuál fue la participación femenina en el sector de confección de Bangladesh para el exitoso desempeño económico del país desde la década de 1980 hasta el presente. Desde la aplicación de una perspectiva analítica beterodoxa y un estudio de caso, se demuestra que no ha habido progreso tecnológico significativo, diversificación productiva y desarrollo económico en Bangladesh al ritmo de las tasas de crecimiento del país. Además, la mayor demanda de mano de obra femenina en la industria de la confección, un sector clave de la economía, no ba sacado a las mujeres de la condición de dependencia o subordinación a los hombres, ya que las desigualdades de género persisten en el mercado laboral del país.
\end{abstract}

Palabras clave: género; comercio; confección; Bangladesh; desigualdad.

\section{Transformations in the International Economy, Trade and Gender: A Case Study of Female Participation in the Bangladeshi Garment Industry}

\begin{abstract}
Based on the premise that the roles of men and women are distinct in the economy, and, at the same time, that they are reinforced by political decisions and by social structure, the objective of this work is to investigate what was the role of female participation in the Bangladeshi garment industry for the country's successful economic
\end{abstract}


performance between 1980s and 2020. Relying on a beterodox analytical perspective and using a case study, I demonstrate that there has been no significant technological progress, productive diversification nor economic development in Bangladesh at the pace of the country's GDP growth rates. In addition, the increased demand for female labor in the garment industry, a key sector of the economy, has not removed women from the condition of dependence or subordination to men, since gender inequalities persist in the country's labor market.

Keywords: Gender; trade; garments; Bangladesh; inequality.

\section{Introdução}

A década de 1970 marcou o início de rápidas transformações na economia internacional relacionadas à reestruturação da indústria, ao aumento dos fluxos de comércio e de capitais, aos processos de internacionalização de empresas, de inovações tecnológicas e diferenciação de produtos. Com a abertura e a integração dos mercados nacionais, governos de diversos países do mundo procuraram oportunidades de ampliar vantagens comparativas e competitivas de produção, adaptando suas políticas industriais e comerciais ao aumento da competição, da velocidade dos fluxos econômicos e da demanda do mercado capitalista global, pautando suas decisões nos pressupostos da agenda econômica neoliberal.

Atraído pelo discurso dos benefícios das reformas econômicas pró-mercado, as quais foram primeiramente aplicadas nos Países Desenvolvidos (PDs), nos anos 1980, Bangladesh, um país essencialmente rural, localizado no Sul da Ásia, começou a levar a cabo processos de abertura do seu mercado nacional, privatização de empresas estatais e ajustes estruturais de sua economia, após um período de fracassadas políticas econômicas. Seu objetivo era promover o crescimento e o desenvolvimento econômico do país através da especialização produtiva voltada às exportações. Por razões históricas, o país tinha expertise na produção de peças de vestuário em larga escala e grande quantidade de mão de obra composta por mulheres, migrantes do campo para as cidades e com baixa qualificação, disposta a trabalhar por baixos salários na linha de montagem de fábricas 


\section{I Patricia Nasser de Carvalho}

manufatureiras locais subcontratadas por grandes empresas transnacionais globais sediadas em países industrializados ou por filiais das mesmas. As reformas econômicas liberais deram impulso definitivo ao setor de vestuário em Bangladesh, e, como consequência disso, houve aumento da demanda de mulheres para compor a força de trabalho, um fator de produção chave que conferiu vantagens de custos relativos à produção de vestuário.

A despeito das persistentes dificuldades socioeconômicas, a economia de Bangladesh não tardou em mostrar bons resultados: o Produto Interno Bruto (PIB) e o PIB per capita cresceram de forma contínua. Houve aumento da população urbana e de oportunidades de trabalho para a mão de obra feminina como em nenhum outro setor da indústria manufatureira. O país se tornou uma importante plataforma produtora e exportadora mundial de vestuário, o que rendeu amplos retornos à indústria e à economia, o surgimento de novas fábricas e o estímulo para mais contratações. Dezenas de milhões de pessoas saíram da situação de pobreza extrema e a economia de Bangladesh se tornou cada vez menos dependente do campo e passou a ser mais dependente das atividades urbanas, como indústria e serviços.

Partindo da premissa de que os papeis de homens e de mulheres são distintos na economia, pois compõem um sistema de relações sociais e culturais no qual a questão de gênero está circunscrita, e, ao mesmo tempo, são reforçadas por decisões políticas e pelo momento histórico em curso, o objetivo deste trabalho é investigar qual foi a participação feminina na indústria de vestuário de Bangladesh para o exitoso desempenho econômico do país da década de 1980 até a atualidade. No escopo das abordagens analíticas heterodoxas sobre comércio internacional, aplica-se aquela que relaciona comércio e gênero e considera em sua análise os diferentes tipos de papeis ocupados por mulheres na economia e na sociedade de todas as nações do mundo. No caso da política comercial, essas abordagens se propõem a responder de que modo a abertura dos mercados para as trocas de bens e serviços afeta as categorias de gênero de maneira distinta. 
Para preencher a lacuna deixada pelos poucos estudos de comércio internacional que relacionam comércio e gênero, a partir da contextualização das mudanças experimentadas pela economia internacional nas últimas décadas e da discussão de um estudo de caso sobre as reformas realizadas na economia bangladeshiana, neste artigo busca-se demonstrar que, a despeito do aumento do nível de emprego feminino no setor de vestuário em Bangladesh, as mulheres permaneceram submetidas à más condições de trabalho nas indústrias e não viram crescer oportunidades de ascensão profissional e social na mesma proporção que o ritmo de contratação e do progresso do desempenho econômico do seu país. Persistem desigualdades de gênero, ainda que o setor de vestuário tenha contribuído para o desempenho positivo da economia e das exportações do país e para a contratação de milhões de mulheres: em geral, os salários das mulheres ainda são inferiores aos dos homens, e mesmo na indústria de vestuário perduram limitações do poder de barganha da força de trabalho feminina, que, em média, continua sendo menos qualificada que a masculina e tem menos oportunidades de ascensão profissional. Ou seja, em geral, ainda existe discriminação de gênero no mercado de trabalho, a qual também é reflexo da condição da mulher na sociedade bangladeshiana.

Na primeira seção são discutidas as rápidas transformações da economia internacional desde os anos 1970, enfatizando as estratégias das empresas em regiões mais e menos industrializadas do mundo. A segunda seção trata do aumento da demanda de mão de obra feminina, a qual se tornou um fator chave de vantagens comparativas para muitas economias em desenvolvimento ou subdesenvolvidas do mundo, influenciando decisões políticas e econômicas nacionais. A terceira seção dedica-se a debater uma perspectiva analítica heterodoxa de comércio internacional, que relaciona comércio e gênero. Cada vez mais difundida, essa abordagem impõe um olhar crítico sobre a condição das mulheres em diversas economias e sociedades, ao considerar o quão desigual ela é em relação aos homens. Geralmente, esse elemento é desconsiderado pelos princípios neoclássicos orientadores da formulação das políticas neoliberais. A quarta seção aborda o estudo de caso e procura associar a importância da indústria de vestuário em Bangladesh com o bom desempenho econômico 


\section{I Patricia Nasser de Carvalho}

do país nas últimas quatro décadas. Por meio da análise de dados de pesquisas empíricas também se contempla qual foi a conjuntura em que ocorreu a abertura comercial desse país desde os anos 1980 e como se deu a proliferação da indústria de vestuário no país. Por fim, a última seção discute a participação das mulheres na força de trabalho bangladeshiana e demonstra que as decisões políticas ligadas ao fortalecimento de vestuário, para além das características estruturais da sociedade, incluindo religião e cultura, moveu-se basicamente pela força de trabalho feminina, e que não se traduziu na diminuição prática das desigualdades de gênero na mesma proporção que o êxito econômico do país nas últimas quatro décadas. Nessa parte, na impossibilidade de fazer pesquisa de campo, foram utilizados trabalhos de investigação de pesquisadores e organizações internacionais dedicados ao tema de modo a explorar evidências que corroborem a tese.

\section{Transformações na economia internacional}

A partir da década de 1970, ocorreram rápidas transformações na economia internacional. Com a ascensão do chamado regime de acumulação flexível - fortemente ligado à agenda econômica neoliberal (Harvey, 1992) - as empresas buscaram se tornar mais competitivas em termos de custos de produção, inovação e diferenciação de seus produtos. O mercado externo ficou mais atrativo para as grandes empresas transnacionais à medida que as economias com oferta de mão de obra abundante e barata, além de outros fatores de produção, se abriam e ofereciam outras vantagens comparativas (Chesnais, 1996). Ao mesmo tempo, na fase final da Guerra Fria, custos de transportes, de comunicação e de informação declinavam mais rapidamente conforme as inovações tecnológicas ampliavam oportunidades de vantagens competitivas e outras economias se descerravam para concorrer no mercado capitalista global. O processo de desregulamentação financeira internacional, encabeçado pelos Estados Unidos e pelo Reino Unido, começou a ganhar níveis e ritmo sem precedentes, reforçando a retomada da ideologia do livre mercado, não somente como força motriz das trocas de bens e de serviços, senão que também da livre mobilidade de capitais (Guttmann, 1998). 
$\mathrm{Na}$ década seguinte, imensos fluxos de investimentos direto estrangeiros (IDE), realizados por grandes empresas globais, as quais se apoiavam em bases transacionais da integração vertical da produção (Caves, 2003), direcionaram-se em maior medida para os países da Ásia e em menor para países da América Latina e da África, principalmente para o setor manufatureiro. Os fluxos de comércio internacional também se ampliaram em função das trocas intrafirma, fortalecendo a interdependência entre os mercados geograficamente dispersos em todo o mundo (Dicken, 2011). A internacionalização da produção, reforçada pela formação das cadeias globais de valor (CGV), gerou uma estrutura de mercados ao mesmo tempo fragmentada, hierarquizada e bastante competitiva nas escalas mundial, regional e local, e muito interrelacionada no âmbito do capitalismo global. Fusões, aquisições, incorporações, associações com firmas de outros países e de outras nacionalidades, além da terceirização (contratação ou subcontratação) da produção e de serviços, tornaram-se estratégias corporativas de empresas globais off shore (Gomes-Casseres, 1998). Retomando as premissas ortodoxas da economia neoclássica, muitos analistas e políticos defensores do neoliberalismo, apontavam que as CGV e a integração dos mercados eram fatores positivos derivados de políticas nacionais que incentivavam a abertura desses mercados, pois resultavam na queda dos custos de produção, no aumento de produtividade, no estímulo à inovação e à difusão tecnológica pela competição, no maior acesso a bens intermediários importados mais baratos, em economias de escala, na geração de empregos, na otimização do lead time e no estímulo ao aumento de salários (Grossmann \& Helpman, 1991; Krueger, 1998), eventos sucedidos pela criação de comércio, crescimento e desenvolvimento econômico dos países.

O discurso de muitos governos de PDs, alavancado pelas supostas oportunidades apresentadas pela abertura do mercado internacional na era da globalização, atraiu Países em Desenvolvimento (PEDs) e Países Menos Desenvolvidos (PMDs). Após décadas adotando políticas de industrialização por substituição de importações e enfrentarem crises econômicas e dificuldades para superar problemas sociais e instabilidade face ao alto endividamento externo nos anos 1970 e 1980, na década seguinte essas nações decidiram adotar diversas reformas 


\section{I Patricia Nasser de Carvalho}

econômicas pró-mercado. Seus representantes procuraram oferecer aos investidores e importadores menores custos de produção, flexibilização das regulações trabalhistas e tributárias e decrescentes barreiras ao comércio, reestruturando as suas políticas industrial e comercial por meio da oferta de subsídios, isenções fiscais, diminuição de subsídios a determinados setores e a realização de acordos de livre comércio. Exceções foram alguns países do Sudeste da Ásia, como Coreia do Sul e Taiwan, cujos governos priorizaram a abertura gradual dos seus mercados a partir da década de 1960, com o compromisso de construir uma indústria doméstica competitiva com o fim de elevar o padrão de vida da população (Wade, 1990).

Essa reestruturação dinâmica da produção teve repercussões na divisão do trabalho, no nível de emprego e de salários, tanto em nível nacional quanto internacional, a partir da contratação por empresas, cujas sedes eram PDs, de serviços de fábricas manufatureiras situadas em PEDs e PMDs especializados na produção de vestuário, tecidos, calçados, brinquedos, componentes eletrônicos e outros bens de consumo, peças e suprimentos para a indústria. Houve também casos de transferência integral da produção manufatureira para essas localidades. Diante da sua situação de subdesenvolvimento e baixo nível de industrialização, havia um grande contingente de mão de obra de baixa qualificação, proveniente do êxodo do campo, disposta a trabalhar na linha de montagem de fábricas manufatureiras locais subcontratadas ou de filiais de grandes empresas transnacionais. Como consequência disso, houve aumento dos fluxos de IDE para esses países, acirrando a competição entre PEDs e PMDs para receber novos investimentos e fechar novos contratos de produção, aumentando a sua participação nas CGV.

Entre os anos 1980 e início dos 2000, alguns PEDs, especialmente os asiáticos, conseguiram aumentar sua capacidade de produzir bens com maior valor agregado à medida que seus governos centralizados e suas burocracias apoiavam projetos nacionais, criavam condições para receber fluxos de IDE de empresas transnacionais globais e realizavam planos de reestruturação e diversificação de suas economias, que incluíam investimentos em infraestrutura e em tecnologia, 
empréstimos, subsídios e qualificação da mão de obra (Amsden, 1989; Evans, 1995). As lideranças desses países ainda diminuíram as barreiras comerciais para que as empresas locais importassem insumos, substituíssem grande parte da produção industrial e exportassem bens manufaturados finais. Por esses motivos, nos anos 1990, Coreia do Sul, Hong Kong, Cingapura e Taiwan alcançaram capacidade de produzir bens finais e serviços de maior valor agregado do que nos decênios anteriores. Na década seguinte, foi a vez da China mudar sua estratégia, deslocando seu foco de quantidade para a qualidade na produção de bens e serviços. Dessa forma, no início dos anos 2000, a produção de manufaturas intensivas em mão de obra passou a se concentrar em países como Vietnã, Camboja e Bangladesh, entre outros, onde os salários ainda permaneciam relativamente baixos, estáveis e vantajosos em termos de custos de produção (Pepermans, 2019).

A reação de PEDs e PMDs com dotações quase idênticas de recursos e fatores foi sua especialização na produção em tipos muito específicos de bens, uma consequência maior de investimentos experimentais individuais de empreendedores privados, os quais inicialmente primaram por fabricar imitações e cópias e depois se especializaram, do que efetivamente do apoio estatal a inovações (Rodrick, 2004). Por esse motivo, todos eles se tornaram muito produtivos em uma gama restrita de produtos, independentemente de suas políticas macroeconômicas ou da atuação das instituições públicas nacionais.

Esses processos também resultaram em crescentes desequilíbrios globais face às diferenças em termos de distribuição, remuneração e capacidade produtiva e de consumo entre PDs industrializados e PEDs e PMDs menos ou pouco industrializados (Dicken, 2011). De fato, a globalização alterou a dinâmica das fronteiras mercantis, implicando em que os bens e serviços produzidos em um país pudessem ser consumidos do outro lado do mundo a custos mais baixos. Todavia, também houve achatamento ou estagnação de salários em determinados setores de vários países do mundo, eliminação de pequenos empreendimentos, negligência de direitos trabalhistas por parte de empresas e governos e flexibilização de contratos, para além das desigualdades globais em termos de capacidade de produção, de consumo 
e de inovação, enfim, de geração de renda. Os níveis de integração dos mercados ao comércio internacional e as matrizes de IDE também não aumentaram de modo uniforme; em muitos países, eles até caíram, sobretudo após a crise econômica internacional de 2007/2008 (Rodrick, 2018). Ainda que diversas economias em desenvolvimento ou subdesenvolvidas tenham se firmado como grandes produtoras de manufaturas trabalho-intensivas, seu mercado ficou ainda mais dependente delas. Nesse contexto, surgiram novas perspectivas analíticas de comércio internacional, com o objetivo de explicar as transformações experimentadas pela economia internacional, as falhas de mercado e suas desiguais consequências.

\section{Abordagens heterodoxas e a "feminização" da mão de obra}

O papel do Estado e das instituições governamentais no processo de industrialização, os conflitos sociais domésticos relativos à distribuição de renda e às condições do ambiente de trabalho, as capacidades de produção e de consumo díspares, o grau de dependência econômica e tecnológica e o papel do conhecimento na determinação do padrão, fizeram com que as trocas internacionais se tornassem objetos de críticas acerca das práticas neoliberais e suas repercussões no comércio internacional desde os anos 1980. Essencialmente, essas análises argumentam que a configuração produtiva mundial dos últimos quarenta anos aumentou a dependência das economias pouco ou não industrializadas em relação aos investimentos de empresas globais, ao capital financeiro, aos empréstimos e à tecnologia com origem nos PDs industrializados (Barrientos, 2007; Panitch \& Gindin, 2012). Afirmam também que o comércio internacional, pautado em vantagens comparativas, favorece a formulação de políticas que causam distorções de preços e participação de forma subordinada, dependente e atrasada de PEDs e PMDs na economia internacional.

Essas perspectivas heterodoxas também constatam que em países com abundância de trabalho de baixa qualificação, os salários médios, 
em geral, não tendem a se elevar significativamente e muito menos conduzem necessariamente à melhora das condições de trabalho (Rodriguez \& Rodrick, 1999). Investigações nessa linha mostram ainda que a renda média do trabalho pode até chegar a ser menor do que antes de uma certa economia fazer parte das CGV, gerando efeitos ineficientes em termos de distribuição de renda em países menos industrializados. Da mesma forma, trabalhos empíricos verificam que em algumas economias as condições do ambiente de trabalho revelaram até propensão a piora. Em muitos casos, a flexibilização da jornada de trabalho e a queda da regulação estatal resultaram na maior vulnerabilidade dos trabalhadores, dada a diminuição da sua proteção social ou poder de negociação salarial (Standing, 1999), na eliminação de setores não-competitivos e na concentração da produção em poucos setores e produtores. Outras pesquisas demonstram ademais que conflitos sociais resultantes do baixo nível de renda média ou de desigualdades de salários geradas após a abertura do mercado criam sinais que ampliam incertezas, as quais inibem outros investimentos produtivos (Larraín \& Vergara, 1998). Há ainda aqueles estudos que concluem que a agenda neoliberal fracassou porque levou a mais exclusão social, pobreza e crises e não aumentou o crescimento econômico da maioria dos países do mundo (Stiglitz, 2002; Gatti et al., 2012).

Olhares críticos sobre a condição da mulher em diversas sociedades do mundo ganharam mais espaço no debate político e acadêmico ao discutir e demonstrar como o gênero se tornou um elemento definidor de decisões políticas e econômicas que influenciam a competitividade das economias em âmbito nacional e internacional. Especialmente a partir dos anos 1990, a Conferência das Nações Unidas sobre Comércio e Desenvolvimento (United Nations on Trade and Development, UNCTAD), assim como a Organização das Nações Unidas (ONU), a Organização Mundial do Trabalho (OIT), o Banco Mundial, a Organização para a Cooperação para o Desenvolvimento Econômico (OCDE), e outras organizações internacionais, além de organizações não governamentais (ONGs), como a Oxfam e o Oversas Development Institute, dedicam-se a pensar abordagens analíticas e realizar trabalhos empíricos que relacionam comércio internacional e gênero, e desafiem modelos econômicos, paradigmas e conceitos tradicionais, 
incorporando as desigualdades entre homens e mulheres, que permeiam sociedades, economias e meios políticos em todo o mundo.

Também difundidas por pesquisadores acadêmicos no âmbito da área de estudos da escola de Economia Feminista, essas abordagens vão além da crítica às premissas e conclusões do mainstream da economia $\mathrm{e}$ se dedicam a produzir novas metodologias e análises que incorporam experiências empíricas referentes à mulher àmodelos econômicos (Floro \& Willoughby, 2016), absorvendo elementos de outras áreas, como Sociologia e Política, agregando preocupações diversas à agenda de temas, como direitos humanos, justiça e impactos de políticas públicas (van Staveren, 2005). Ademais, essas perspectivas analíticas críticas enfatizam que a disponibilidade e a condição da mulher e a sua participação em uma determinada economia e sociedade impactam diretamente a alocação interna dos fatores de produção, a formulação das políticas industrial e comercial de um país e sua especialização e eficiência produtiva face à competição internacional e as estratégias de inserção internacional por ele escolhidas. Os benefícios da maior abertura de um mercado ao comércio dependem da demanda interna e externa e das normas sociais vigentes em cada país relacionadas à gênero (Fontana, 2003).

Quando as empresas globais contratam ou subcontratam serviços de fábricas locais em países onde os salários pagos às mulheres em média são mais baixos que os dos homens, elas se beneficiam dessas vantagens de custos relativos. Dado o grande contingente de mulheres disposta a trabalhar nas fábricas localizadas em várias economias semiperiféricas e periféricas ${ }^{1}$ situadas no Sul Global, mesmo que por salários e condições inferiores aos dos homens, desde os anos 1960, a força de trabalho masculina foi sendo substituída pela feminina em várias dessas economias, processo que ganhou mais força a partir da década de 1980 (Standing, 1999). Setores manufatureiros ali

\footnotetext{
1 No Sistema Interestatal capitalista, a economia está em constante expansão e há uma divisão do trabalho entre o centro desenvolvido e industrializado e a semiperiferia, que tem certo nível de industrialização, e a periferia é pouco industrializada. As duas últimas categorias incluem PEDs e PMDs.
} 
situados, em sua maioria especializados na produção de têxteis, vestuário e calçados e na montagem ou na produção de outras manufaturas básicas destinadas à exportação, repercutiram na exploração dessas desigualdades nas últimas décadas. Em vista disso, as estratégias de competitividade de empresas há muito se "aproveitam" das situações de desigualdades estruturais entre homens e mulheres (e todas as suas respectivas consequências, como a desigualdade salarial, por exemplo), concentrando investimentos em setores trabalho-intensivos de baixo nível de complexidade industrial, a fim de utilizar mão de obra feminina como importante - e, em muitos casos a mais importante - fonte de vantagens comparativas.

Esse fenômeno denominado "feminização" da força de trabalho - que ocorre quando há aumento da demanda por mão de obra feminina, que se coloca como um fator de produção abundante e barato proporcionalmente aos homens -, por grandes empresas globais contratam ou subcontratam serviços de fábricas localizadas em PEDs ou PMDs. Essas empresas tomam o trabalho feminino como um elemento flexível, tornando-o mais precário e inseguro (Akorsu, 2016). Esta é uma característica da reestruturação produtiva mundial e repercute de forma diferente em diferentes países e dentro dos países. Por um lado, o aumento do nível de emprego fomentado pelas exportações estabelece forte conexão entre a formulação da política industrial e comercial de uma nação e os salários médios pagos, os quais repercutem nos montantes exportados (UNCTAD, 2014). Por outro lado, nos mercados onde a oferta de trabalho é elástica, especialmente em razão da grande quantidade de mão de obra feminina, os salários médios tendem a ser menores que os pagos aos homens ou às mulheres de outros países e até mesmo insuficientes para cobrir gastos básicos.

Usualmente, nessas economias, há segregação por gênero no mercado de trabalho, e os salários das mulheres continuam baixos em termos absolutos ou aumentam menos proporcionalmente à elevação da produtividade industrial. O nível inferior da remuneração feminina vis-à-vis a masculina é justificado por políticos e empresários em razão das características do setor e não pelas desigualdades de gênero (Fontana, 2003). A "feminização" da mão de obra também é expli- 
cada, em grande parte, pelo fato de que muitos empresários locais acreditam que as mulheres são mais adaptáveis do que os homens para desempenhar certos tipos de serviços repetitivos e minuciosos, que exigem paciência.

Pesquisas de diversas instituições mostram que, em geral, nos países das regiões semiperiféricas e periféricas do mundo, as mulheres têm menor escolaridade e treinamento técnico, dedicam-se mais a ocupações de tempo parcial ou têm empregos com contratos mais flexíveis e intermitentes, de maior rotatividade que nos PDs industrializados, e no limite, estão mais propensas a aceitarem subempregos e trabalhos informais do que os homens (OECD, 2019; ILO, 2019; UNCTAD, 2014). Dessa forma, elas têm menos oportunidades no mercado de trabalho formal do que os homens. Visto que as ocupações individuais são hierarquizadas, há segregação por níveis de carreira em uma fábrica, empresa ou instituição, as quais, muitas vezes, variam com o gênero (Menzel \& Woodruff, 2019). Diante desse quadro, a força de trabalho feminina tende a se concentrar em poucos setores e a ter muito mais dificuldades para ascender na carreira que a força de trabalho masculina. Os homens, por sua vez, são mais bem distribuídos entre setores, ocupações e atividades produtivas (World Bank, 2012) e têm mais chances de alcançar e preencher altos cargos no mercado formal, de realizar atividades em áreas intensivas em capital ou funções de maior complexidade, de ser promovidos, ter mais mobilidade no mercado de trabalho e, por conseguinte, de receber melhores remunerações do que as mulheres.

\section{Uma abordagem heterodoxa: a perspectiva comércio e gênero}

Segundo a ONU, gênero se refere aos "papeis e atributos associados a ser homem ou ser mulher, os quais são construídos e aprendidos através de processos de socialização; são específicos e variam dependendo do contexto cultural e social" (UNICEF, 2017, p. 2). Dado que a igualdade de gênero reconhece diferentes interesses, necessidades e prioridades para homens e mulheres e que o lugar que cada um 
ocupa na sociedade deve ser levado em consideração na formulação de políticas públicas, sendo a igualdade um fator que repercute no desenvolvimento de uma nação, as desigualdades de gênero se referem à manifestações que criam desvantagens ou situações de subordinação para as mulheres. No mercado de trabalho, a discriminação por gênero é uma forma de as mulheres terem acesso somente a uma limitada gama de ocupações e os salários pagos a elas, muitas vezes, subestimam a sua capacidade produtiva e/ou meritocrática.

A ideia de levar em conta as diferenças de gênero, apresentadas pelas investigações sistemáticas feitas pela UNCTAD (2014), por exemplo, pautada nas conclusões de vários outros pesquisadores e instituições, reconhece que diferentemente das teorias neoclássicas e também de algumas abordagens econômicas heterodoxas, os papeis de homens e de mulheres são distintos na economia, pois eles são parte de um sistema de relações políticas, sociais e culturais no qual a questão de gênero está circunscrita (Razavi \& Hassim, 2006). Assim, processos de socialização, divisão de responsabilidades familiares, acesso e controle de recursos e participação em processos de tomada de decisão têm ligações diretas com as diferenças de gênero, e, ao mesmo tempo, são reforçadas pela estrutura econômica, política, cultural e social e pelo período histórico em curso (UNCTAD, 2014, pp. 3-4). Há, assim, em cada país do mundo, relações entre normas sociais e de poder que variam de acordo com diversos aspectos, inclusive com o gênero.

É possível resumir que a perspectiva que relaciona comércio e gênero, difundida pela UNCTAD e por diversos analistas, como Benería et al. (2015) e van Steveren (2005), ainda é relativamente nova, e admite que: a) as desigualdades de gênero tendem a influenciar as estratégias de competitividade industrial das economias - incluindo as escolhas de governos e empresas e instrumentos de políticas industrial e comercial -, uma vez que uma gama particular de medidas deve ser traduzida no desempenho econômico-comercial desejado (ex-ante); b) uma vez definidas as estratégias de competitividade das economias, os resultados distributivos do comércio internacional variam de acordo com cada categoria de gênero dentro de um país, isto é, 
em um mesmo país, homens e mulheres são afetados pelas mudanças nas políticas e padrões de comércio de formas diferentes (ex-post).

Ainda segundo essa perspectiva, comércio é um importante aspecto do processo de globalização, que proporciona crescimento e desenvolvimento aos países, mas pode reverberar em impactos tanto positivos quanto negativos para a igualdade de gênero (Fontana, 2003). Esses impactos estão relacionados a oportunidades de emprego e ascensão profissional, qualificação da mão de obra, nível de salários, condições e qualidade de trabalho, nível de pobreza, acesso a serviços básicos como educação, saúde, pensões, entre outros.

Dessa ótica, constata-se que em todos os países do mundo, a segregação por gênero se reflete na confluência de mão de obra majoritariamente feminina na prestação de serviços domésticos, na produção agrícola e de alimentos, nos cuidados com a casa ou com pessoas doentes ou idosas, tanto no seu núcleo familiar, onde não há remuneração ("trabalho não-pago"), ${ }^{2}$ quanto fora dele. Além disso, face às demandas domésticas e à estrutura da sociedade e da economia em que vivem, frequentemente as mulheres têm menor acesso à herança, terra, educação, formação técnica, e ao crédito (UNCTAD, 2014).

Dados da OIT de 2017 mostram que em todas as regiões do mundo, por razões diversas, as mulheres constituem uma parcela maior de trabalhadores que "contribuem para as famílias" (ILO, 2018) porque executam proporcionalmente mais trabalho não recumerado nãopago (atividades como cozinhar, limpar, tomar conta de crianças e de idosos, de adultos doentes e/ou incapacitados, trabalhar na lavoura doméstica, cuidar da casa, etc., sem remuneração) que os homens. Há análises que identificaram, de uma amostra de 75 países, que em todos, sem exceção, as mulheres dedicam, em média, 3,2 vezes mais tempo do que os homens para realizar atividades não remuneradas não-pagas (Charmes, 2019). A mesma conclusão chegou a OCDE, que recentemente mediu o tempo médio diário gasto por mulheres

\footnotetext{
2 Fazem parte atividades que são reconhecidas como trabalho, mas geralmente não estão incluídas no Sistema de Contas Nacionais (OECD, 2019).
} 
e por homens em atividades que demandam trabalho reumerado e não recumerado pago e não-pago nas diversas regiões do mundo. $\mathrm{Na}$ figura abaixo, é possível perceber essas diferenças na média global de tempo despendido no ano de 2018 em todas as regiões, com destaque para a região do Sul da Ásia (figura 1).

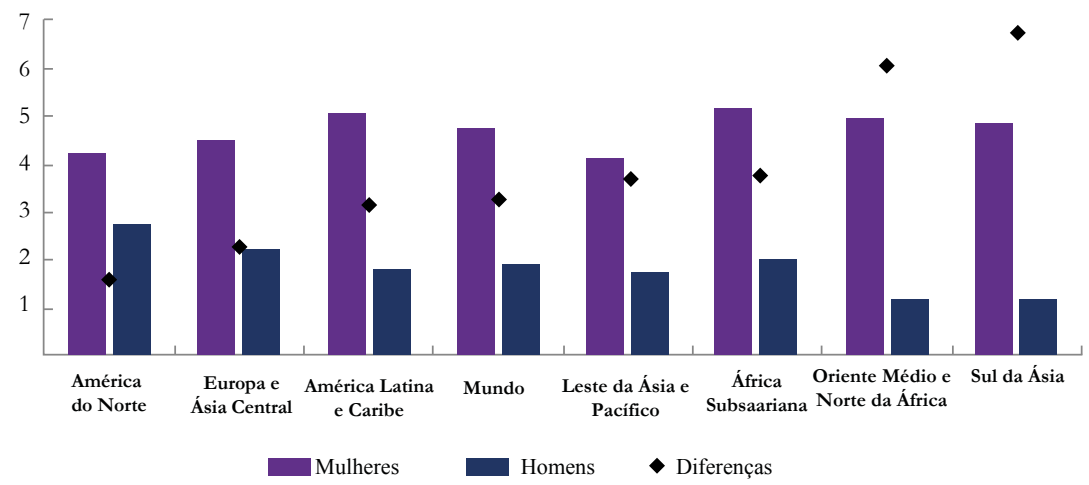

Figura 1. Diferenças de tempo médio de trabalho (remunerado e não remuneradopago e não-pago) despendido diariamente por homens $e$ mulheres nas diferentes regiões do mundo (em horas), em 2018

Fonte: OECD, 2019.

Quando as mulheres assumem também o trabalho remunerado fora de casa, enquanto que ao homem não é atribuído o trabalho não remunerado domiciliar na mesma proporção, o resultado é o acúmulo de tarefas por parte delas. Em vista das dificuldades de equilibrar suas obrigações, é provável que as mulheres sejam empregadas em tipos de trabalhos mais flexíveis e, logo, mais precários do que os homens porque precisam dar conta de todas as atividades. Se realizam apenas trabalho não remunerado na unidade familiar, elas se encontram numa situação de vulnerabilidade econômica e social ainda maior, pois não têm acesso a nenhuma fonte autônoma de renda e dependem da renda do homem, seja seu pai, irmão ou esposo.

Nos PEDs e PMDs, onde o mercado de trabalho informal muitas vezes é a principal fonte de emprego, a proteção social, como a concessão de licença maternidade, é limitada ou não é oferecida (OECD, 2019). 
Em determinadas sociedades patriarcais, costumes e normais sociais, como casamentos arranjados e realizados precocemente, além de conflitos familiares advindos de trabalhos fora de casa, também impedem as mulheres de conciliar o trabalho remunerado com o trabalho não remunerado, promovendo uma condição de dependência ou subordinação em relação aos homens. Verifica-se, assim, que entre os trabalhadores com renda, geralmente há maior tendência de que as mulheres se empreguem na informalidade ou em subempregos e sejam contratadas para realizar tarefas menos valorizadas do que os homens. Nas economias onde a infraestrutura e a tecnologia são pouco desenvolvidas, muitas vezes o trabalho operacional pesado pode fazer com que muitas mulheres sofram lesões, deficiências e outros danos físicos ou mentais (Butt et al., 2018).

Portanto, há elementos que obstaculizam a igualdade de gênero em termos verticais, relacionados a fatores ligados a oportunidades e ascensão profissional, e diferenças em nível horizontal, que variam de país para país, conforme a história e a sociedade, mas também dentro de um mesmo país. Essa última categoria agrega, para além de gênero, raça, religião, etnia e idade. Certamente, esses fatores contribuem para que muitas mulheres ainda se encontrem em posição de inferioridade frente aos homens no mercado de trabalho de diversas sociedades do mundo (Tran-nguyen \& Zampetti, 2004).

Resultados e conclusões de pesquisas empíricas a respeito das desigualdades de gênero e sua relação com o comércio internacional são inúmeras e vão na contramão dos argumentos neoliberais. Por exemplo, a UNCTAD (2014) constatou que nos PDs, o livre comércio abriu oportunidades para o empoderamento feminino ao criar mercados para seus produtos e prover empregos formais. No entanto, na maioria das vezes, nos PEDs e PMDs, efeitos positivos da abertura comercial, como elevação de salários, não aconteceram na mesma proporção e velocidade da contratação da mão de obra. Há casos em que eles até caíram. Isso porque os bens nacionais provenientes de setores intensivos em mão de obra foram confrontados com a competição dos bens similares importados mais baratos ou de qualidade mais alta. Especialmente em economias semiperiféricas, como as do Sul e 
Sudeste da Ásia, voltadas para a produção e exportação de bens de consumo não-duráveis, onde as desigualdades de gênero são grandes por razões históricas e culturais, estudos de Benería et al. (2000) e van Staveren (2013) concluíram que as diferenças de salários entre homens e mulheres foram aprofundadas com a abertura comercial e a especialização produtiva das últimas três décadas.

Investigações como a de Seguino (2002), por exemplo, mostraram empiricamente que pode haver uma correlação positiva entre o viés de gênero no mercado de trabalho e o crescimento econômico. As economias com as maiores diferenças salariais de gêneros na Ásia, todos importantes mercados exportadores, foram as que mais cresceram entre os anos 1990 e 2000. Na mesma linha, segundo Freeman (2000), a prestação de serviços por mulheres em áreas da produção voltadas à exportação como partes das CGV, também foi fundamental para o crescimento econômico de vários PEDs onde havia um grande contingente de mulheres desempregadas, a maior parte delas migrantes do campo. Neste sentido, segundo esse autor, em países em crise econômica ou buscando sobreviver em meio à forte competição produtiva na era da globalização, a "feminização" da força de trabalho pode ser um caminho eficiente para garantir produção fabril em larga escala.

Ghosh (2002) evidenciou tendência de flexibilização das leis trabalhistas de contratação de mulheres no final dos anos 1990 no contexto de crescimento econômico de grandes fornecedores mundiais de manufaturas, como China e México. Seguino e Grown (2006) averiguaram que o poder de barganha das mulheres nas fábricas localizadas em PEDs e PMDs, os quais fazem parte das CGV manufatureiras, manteve-se muito fraco nas últimas duas décadas, a despeito de que essas unidades fabris tenham se espalhado por vários mercados do mundo e, em certo sentido, os salários médios aumentaram. Por meio de uma ampla análise sobre o mercado de trabalho na China, Klugman e Wang (2020) concluíram que embora os investimentos em capital humano tenham avançado muito em termos de crescimento da empregabilidade formal e remuneração feminina naquele país, e ainda com o rápido crescimento econômico experimentado desde 
sua abertura econômica, iniciada no final dos anos 1970, ainda há discriminação contra mulheres enraizada em normas sociais e culturais.

A pesquisa de Kabeer (2012) demonstra que o crescimento econômico por si só não é suficiente para promover a igualdade de gênero, pois as mulheres são as maiores vítimas do processo de liberalização comercial nos PEDs e PMDs, uma vez que persistem desvantagens para elas no mercado de trabalho em relação aos homens, mesmo quando seu salário médio cresce. Goldin (2014) afirma que desde o início dos anos 2000, as diferenças salariais médias entre homens e mulheres vêm decrescendo em todo o mundo à medida que essas últimas passaram a estudar, embora elas ainda prefiram tipos de trabalho com horários mais flexíveis, o que em geral, implica em remunerações mais baixas que os homens em vários setores da economia. Isso acontece porque as firmas inclinam-se a remunerar melhor aqueles trabalhadores que dedicam mais tempo às atividades laborais.

\section{A indústria de vestuário em Bangladesh e sua importância econômica}

Localizada no Sul da Ásia, Bangladesh é o oitavo país mais populoso do mundo, abrigando cerca de 163 milhões de habitantes de diferentes grupos sociais, étnicos e religiosos. Dhaka é sua capital e a maior cidade, onde vivem 15 milhões de pessoas. O país é considerado um PMD de baixa renda média pelo Banco Mundial: seu PIB per capita em 2018 foi de US\$1.698,26 (a US\$ correntes) ${ }^{3}$ (World Bank, 2019), a maior parte de sua população vive abaixo da linha de pobreza ${ }^{4}$ e os níveis de escolaridade e de saúde são muito baixos. Por esses e outros motivos, Bangladesh ocupa o $138^{\circ}$ lugar no ranking mundial de IDH global $(0,608)$, entre 189 países, conforme dados mais recentes de 2017 publicados pelo Programa das Nações Unidas para o Desenvolvimento (PNUD).

\footnotetext{
3 Refere-se a valores de 6 de setembro de 2019.

4 O parâmetro é a linha de pobreza mundial estabelecida pelo Banco Mundial, em 2015, de US\$1,90 por pessoa por dia.
} 
A despeito das persistentes dificuldades socioeconômicas, o PIB e o PIB per capita bangladeshianos têm crescido significativamente, levando à mídia e os organismos internacionais, como o Fundo Monetário Internacional (FMI), a caracterizarem um boom da economia bangladeshiana (IMF, 2018), sobretudo, nos últimos anos, uma vez que o país apresenta taxas expressivas de aumento do PIB até mesmo maiores que a Índia, ${ }^{5}$ as maiores taxas de crescimento econômico da região. A taxa média de crescimento anual do PIB nos últimos dez anos é de 6,5\% e somente em 2018 o país cresceu 7,86\%, alcançando o valor de US $\$ 274,025$ bilhões (World Bank, 2019). Segundo o Banco Mundial, Bangladesh também conseguiu reduzir drasticamente a sua taxa de pobreza: de 44,2\% em 1991 para 19\% em 2007 e $9 \%$ em 2017, o que significa que entre 40 e 50 milhões de pessoas saíram da linha da pobreza extrema no país. $O$ PIB per capita também cresceu de modo significativo. O desempenho positivo do PIB e do PIB per capita nas últimas quatro décadas podem ser observados na figura 2 .

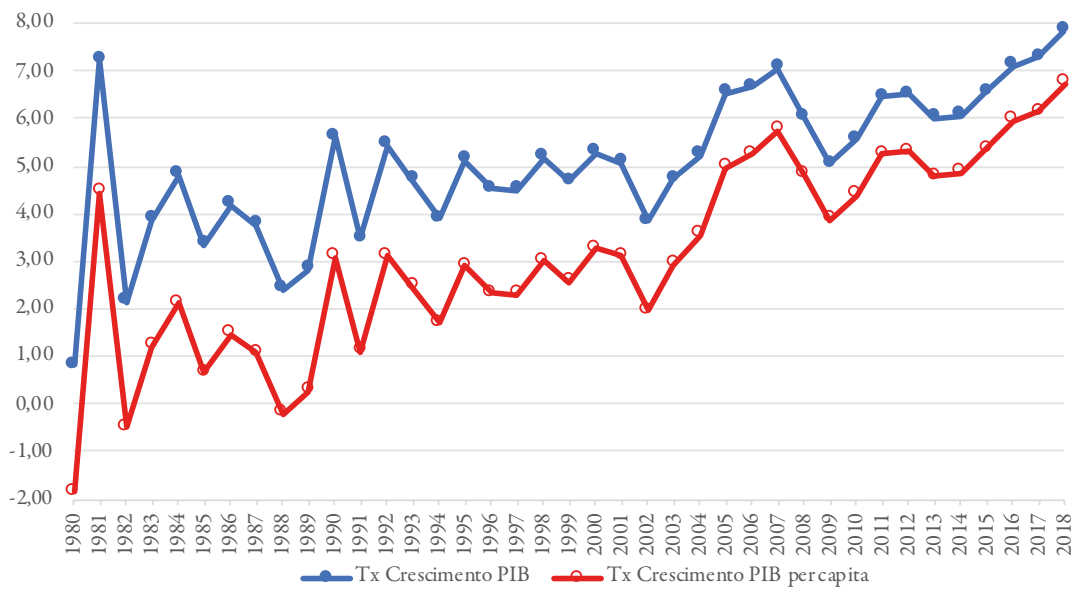

Figura 2. Taxa de crescimento do pib e do PIB per capita anual de Bangladesh (em US\$, 1980-2018)

Fonte: elaboração própria a partir de dados do World Bank (2019).

\footnotetext{
5 Segundo o Banco Mundial, Bangladesh cresceu 7,11\% (2016); 7,28\% (2017) e 7,86\% (2018). A taxa de crescimento econômico da Índia, no mesmo período, foi de 8,17\% (2016); $7,16 \%$ (2017) e $6,81 \%$ (2018).
} 
A produção para exportação de vestuário teve considerável importância para esse excelente desempenho econômico de Bangladesh, apesar das precárias condições regulatórias e de infraestrutura e do incerto ambiente político do país. Atualmente, o país é o segundo maior exportador mundial de peças prontas de vestuário, atrás apenas da China. ${ }^{6}$ Esse setor, que cresce há décadas e continua sendo anualmente aquele com melhor desempenho em termos de participação em valores (US\$) nas exportações totais, representa mais de $80 \%$ de todas as mercadorias que Bangladesh exporta (em 1983 não chegava a 1\%). Em 2018, o valor das exportações de vestuário alcançou a marca de US $\$ 32$ bilhões (WTO, 2019), sendo que os maiores mercados importadores foram: União Europeia, Estados Unidos e Canadá, os quais juntos comparam mais de $85 \%$ das peças de vestuário de Bangladesh (BGMEA). ${ }^{7}$ Em termos percentuais, as exportações mais que triplicaram entre 2008 e 2018, como é possível verificar na tabela 1.

Tabela 1. Participação dos10 principais exportadores de vestuário do mundo (2000-2018)

\begin{tabular}{|l|c|c|c|c|c|c|c|c|}
\cline { 2 - 11 } \multicolumn{1}{c|}{} & $\begin{array}{c}\text { Valor } \\
\text { (em US\$bilhões) }\end{array}$ & \multicolumn{3}{c|}{$\begin{array}{c}\text { Participação nas } \\
\text { exportações mundiais (\%) }\end{array}$} & \multicolumn{3}{c|}{$\begin{array}{c}\text { Diferena anual } \\
\text { (\%) }\end{array}$} \\
\hline $\begin{array}{l}\text { Países } \\
\text { Exportadores }\end{array}$ & $\mathbf{2 0 1 8}$ & $\mathbf{2 0 0 0}$ & $\mathbf{2 0 0 5}$ & $\mathbf{2 0 1 0}$ & $\mathbf{2 0 1 8}$ & $\mathbf{2 0 1 6}$ & $\mathbf{2 0 1 7}$ & $\mathbf{2 0 1 8}$ \\
\hline China & 158 & 18,2 & 26,6 & 36,6 & 31,3 & $-9,00$ & -1 & 0 \\
\hline Bangladesh & 32 & 2,6 & 2,5 & 4,2 & 6,4 & 8 & 2 & 11 \\
\hline Vietnã & 32 & 0,9 & 1,7 & 2,9 & 6,2 & 5 & 21 & 13 \\
\hline Índia & 17 & 3,0 & 3,1 & 3,2 & 3,3 & -1 & 2 & -11 \\
\hline Turquia & 16 & 3,3 & 4,2 & 3,6 & 3,1 & 0 & 0 & 4 \\
\hline Hong Kong & 14 & 5,0 & 2,6 & 0,1 & 0 & $-15,0$ & $-8,0$ & $-4,0$ \\
\hline Indonésia & 9 & 2,4 & 1,8 & 1,9 & 1,8 & -2 & 10 & 9 \\
\hline Camboja & 8 & 0,5 & 0,8 & 0,9 & 1,6 & 12 & 8 & 14 \\
\hline Estados Unidos & 6 & 4,4 & 1,8 & 1,3 & 1,2 & -7 & 0 & 5 \\
\hline
\end{tabular}

Fonte: adaptado de WTO (2019, p. 91).

6 Este dado não considera a União Europeia, que é um bloco econômico. Se fosse considerada, ela seria o $2^{\circ}$ maior exportador do mundo, com participação de 28,4\% (2018) (WTO, 2019, p. 91).

7 Bangladesh Garment Manufacturers and Exporters Association (BGMEA). [http://www.bgmea. com.bd/]. 
As figuras 3 e 4 mostram o aumento sustentado do volume das exportações de vestuário de Bangladesh em relação ao total exportado (em US $\$$ e $\%$ do total exportado) e em relação ao PIB total.

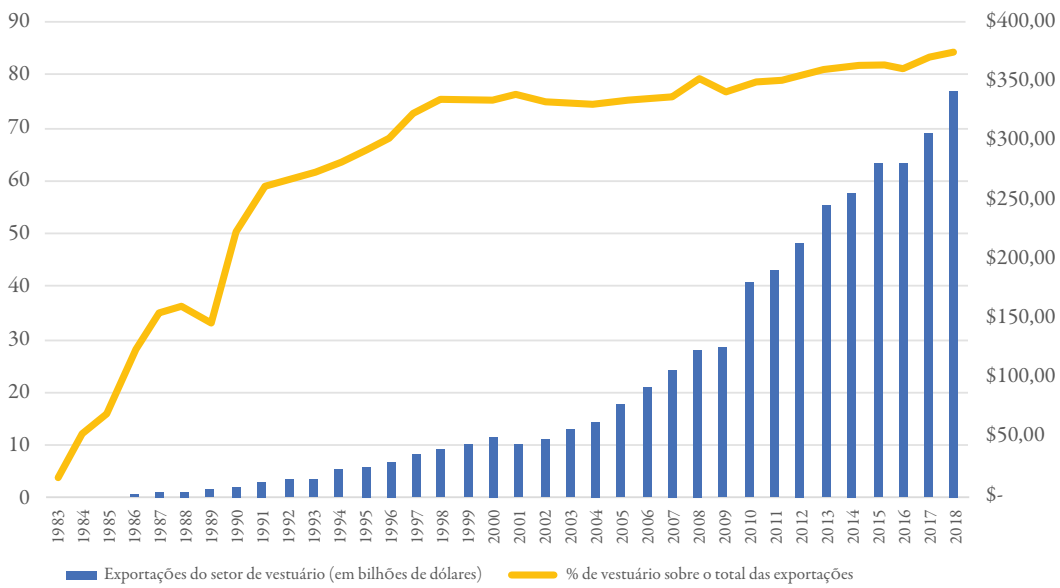

Figura 3. Exportações de vestuário de Bangladesh (em US\$ e \% do total exportado, 1983-2018)

Fonte: elaboração própria com dados do BGMEA.

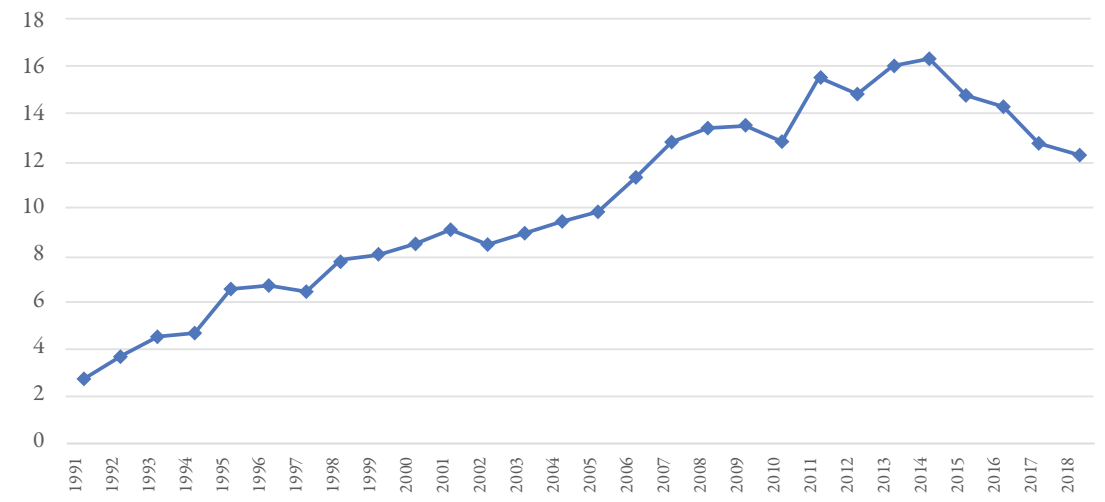

Figura 4. Contribuição das exportações de vestuário para o PIB de Bangladesh (\%, 1991-2018)

Fonte: elaboração própria com dados do Export Promotion Bureau (EPB) do BGMEA. ${ }^{8}$

\footnotetext{
8 O BGMEA não disponibiliza dados da década de 1980 em sua página web. Nos últimos anos, o governo de Bangladesh tem se empenhado em diversificar mais a economia e as exportações do país para as áreas de serviços (tecnologia da informação e farmacêutica). Por isso, a participação do setor de vestuário no PIB tem caído proporcionalmente.
} 
A partir da década de 1980, Bangladesh passou a ter crescente participação no mercado mundial de vestuário, cuja produção é pouco fragmentada porque exporta bens finais. Considerando as vantagens comparativas desse mercado, diversas grandes empresas de origem estrangeira, proprietárias de famosas marcas globais, ampliaram as suas encomendas de camisetas, calças, shorts, jaquetas, agasalhos, roupas esportivas e produtos semelhantes para fábricas bangladeshianas.

Se em 1980 havia em Bangladesh por volta de 50 indústrias de vestuário (Kabeer, 2012), em 1984 eram 380, em 2012 mais de 5000 e em 2018 eram 4621 (BGMEA), que atendiam a marcas como Inditex, H\&M, Marks \& Spencer, C\&A, Victoria Secrets, Gap e Benetton. Desse modo, a taxa de crescimento do número de fábricas chegou a mais de $1000 \%$ no período, a despeito da queda relativa nos últimos cinco anos, quando o país passou a sofrer concorrência de outros mercados asiáticos, como Vietnã, Paquistão, Camboja e até mesmo de africanos, como Marrocos, Etiópia e Quênia, ${ }^{9}$ para além da China, que desde o início dos anos 2000, firmou-se de longe como o maior mercado produtor mundial de vestuário ${ }^{10}$ (Pepermans, 2019), com mais ou menos 31\% do market share mundial de 2018 contra pouco mais de $6 \%$ de Bangladesh (BKMEA, 2018; WTO, 2019). Recentemente, as autoridades bangladeshianas também passaram a aplicar regras mais rígidas de fiscalização no que se refere às condições de trabalho nas fábricas, fechando aquelas que não cumpriam com os padrões legais. Por fim, a introdução de máquinas que substituíram tarefas que antes eram principalmente realizadas por trabalhadores pouco qualificados foi uma importante mudança estrutural recente dessa indústria (Raihan \& Bidisha, 2018).

Todas as informações mencionadas acima mostram que, desde os anos 1980, o setor de vestuário tem importante participação na produção industrial de manufaturas sendo um setor chave para o desempenho

\footnotetext{
9 A intensificação da concorrência internacional provocou a redução do número de fábricas de vestuário em Bangladesh, de acordo com a BGMEA.

10 Desde a adesão da China à OMC, em 2001, o setor de vestuário chinês cresceu muito. Incluindo vestuário e têxteis, o país fornece $2 / 3$ de todos esses produtos para o mercado mundial (Pepermans, 2019).
} 
global das exportações e do PIB bangladeshianos (Rahman \& Sayeda, 2016), dada a sua grande representatividade na economia do país e a concentração setorial das suas exportações, embora o valor agregado dos bens finais tenha reduzido ao longo das décadas.

A indústria de vestuário em Bangladesh teve origem em 1971, ao final da guerra de independência do país contra o Paquistão. A estratégia de política econômica e comercial protecionista foi perseguida pelo governo da época com o objetivo de melhorar a posição da balança de pagamentos do país e proteger as indústrias nacionais (Raihan, 2008). Entretanto, os resultados não foram positivos e essa década foi marcada por desemprego, pobreza, fome e corrupção.

A partir de meados da década de 1980, o regime de comércio bangladeshiano experimentou drásticas mudanças, quando foi iniciado o processo de liberalização econômica moderada, que fez parte do programa geral de reformas nacionais apoiado pelo FMI e pelo Banco Mundial. Sua meta era promover crescimento e desenvolvimento através de exportações e privatizações de empresas estatais, a fim de remodelar o ambiente da indústria nacional. Outros incentivos, como crédito facilitado e licenças para exportar, também foram colocados no mercado à disposição de empresários. O governo ainda implantou uma série de reformas econômicas para criar um ambiente mais atrativo para o IDE (Yunus \& Yamagata, 2012), incluindo as políticas monetária, fiscal e cambial (Raihan, 2008), a criação de zonas de promoção às exportações, ou seja, parques industriais preparados e financiados pelo setor público para a produção de bens manufaturados. Como consequência disso, a economia de Bangladesh, até então essencialmente agrária, começou a passar por uma transformação estrutural (Ahmed et al., 2014).

Na década de 1990, a abertura econômica foi acentuada, o que resultou no aumento do número de indústrias de proprietários locais. $\mathrm{O}$ setor público manteve o suporte às indústrias desse setor, baixando tarifas e concedendo isenção de impostos para importação de maquinário, matérias-primas, tintas e outros produtos químicos, além de que aprovou empréstimos de longo prazo para incentivar a produção, 
embora os investimentos privados tenham sido essenciais (Adnan et al., 2015). A despeito das diversas alternâncias de partidos políticos e de governo no poder central de Bangladesh no decorrer das décadas, a política econômica do país permaneceu estável e consistente, favorecendo os processos de liberalização e crescimento econômico puxados pelas exportações. Se em 1980, as atividades agrícola e industrial compreendiam cerca de $32 \%$ e $21 \%$ do PIB de Bangladesh, respectivamente, em 2005, suas posições relativas haviam mudado: agricultura representava $20 \%$ do PIB em comparação com $27 \%$ da atividade industrial. Em 2018, o setor agrícola era responsável por 13\% do PIB e a indústria por $25 \%$ e, portanto, o setor de serviços contribuía com mais de 50\% para o PIB de Bangladesh (World Bank, 2019).

Após a indústria de vestuário em Bangladesh ganhar fôlego e as reformas econômicas pró-mercado darem impulso definitivo a ela, outro fator foi determinante para o seu desempenho: o grande contingente de mão de obra feminina jovem, vulnerável, pouco escolarizada, com pequena esperança de inserção no mercado formal de trabalho, buscando deixar as condições de pobreza extrema do campo e disposta a aceitar salários baixos e alta carga de trabalho nas cidades. Consideradas mais dóceis e complacentes que os homens para trabalhar em serviços repetitivos (Ahmed, 2004), fisicamente exigentes e que demandavam pouca capacitação, a escolha dos empresários pela mão de obra feminina nas fábricas de vestuário em Bangladesh foi deliberada. Desde os anos 1980, o setor de vestuário gradativamente contratou mais mulheres e se tornou um ramo tradicional de força de trabalho feminina, na contramão do resto da indústria do país, que continuou preferindo empregar homens (Haque et al., 2015).

Além disso, um pacto da elite bangladeshiana, composta por governo, burocracia e empresários criou um ambiente viável, de consenso, que protegeu seus ganhos e se manteve com base na relação de confiança entre fornecedores e compradores, garantindo que o setor de vestuário crescesse em Bangladesh. Enfim, as políticas industrial e comercial de Bangladesh se valeram de condições ex-ante, as quais reverberaram positivamente sobre o desempenho econômico do 
país. Seus diferentes impactos ex-post sobre homens e mulheres são discutidos na última seção.

\section{A participação feminina no setor de vestuário de Bangladesh}

Estimativas de 2018 apontam que 36\% do total de mulheres com mais de 15 anos participavam da força de trabalho - número notável se comparado aos 8\% da metade dos anos 1980 (Raihan \& Bidisha, 2018) - mas ainda muito inferior à masculina, que é de 82\% (World Bank, 2019). Mais baixo ainda é o percentual que trabalha no setor de manufaturas em 2018: somente em torno de 15\% eram mulheres. O setor de vestuário é uma exceção.

Especificamente nele, havia pouco mais de 4 milhões de pessoas empregadas em 2015, sendo que $90 \%$ eram mulheres. Ele se firmou como a atividade urbana que mais emprega mão de obra feminina no país desde 2010 (Farole \& Cho, 2017). Esse percentual, que pouco mudou atualmente, é o mais alto entre os países do Sul da Ásia, os quais também se especializaram na produção de vestuário. Na tabela 2 são apresentados dados comparativos do emprego assalariado da mão de obra feminina de Bangladesh no setor de vestuário no ano de 2015.

Tabela 2. Empregabilidade feminina nas indústrias de vestuário nos países do Sul da Ásia em 2015 (\%)

\begin{tabular}{|l|c|c|}
\hline \multicolumn{1}{|c|}{ País } & $\begin{array}{c}\text { Total de trabalhadores } \\
\text { (em milhões) }\end{array}$ & \% de mulheres \\
\hline Bangladesh & $4,2^{11}$ & 90 \\
\hline Sri Lanka & 3,1 & 81 \\
\hline Índia & 5,3 & 38 \\
\hline Nepal & 5,2 & 18 \\
\hline Paquistão & 9,1 & 15 \\
\hline
\end{tabular}

Fonte: Adnan et al. (2015, p. 27) com dados do BKMEA (2015).

\footnotetext{
11 Nesse ano, a População Economicamente Ativa (PEA) de Bangladesh era estimada em pouco mais de 80 milhões de pessoas.
} 
De fato, o setor de vestuário criou oportunidades de negócios, ampliou contratações e estimulou projetos de infraestrutura e o aumento do PIB e da renda per capita do país. Parte da explicação para esse desempenho está nos números acima, que podem ser traduzidos no processo de "feminização" da mão de obra, dado o alto percentual de mulheres empregadas na produção de vestuário em Bangladesh. Esse é um elemento importante a ser constatado porque, no geral, a empregabilidade da força de trabalho ainda é desfavorável para as mulheres em Bangladesh. Apesar do seu aumento expressivo nas últimas décadas, a taxa de participação feminina no mercado de trabalho do país tem se mantido muito inferior à taxa de participação masculina, a qual é semelhante a de economias avançadas.

Para além disso, dados da tabela 3 evidenciam uma redução no nível de emprego feminino em atividades agrícolas desde o final da década de 1990, embora de modo menos proporcional ao masculino. Nos últimos anos (desde 2013), houve uma inversão dessa tendência, já que a participação das mulheres em empregos de baixa produtividade e atividades agrícolas mal remuneradas cresceu frente a um correspondente declínio nos empregos industriais, inclusive no setor de manufaturas, diminuindo a absorção de mão de obra feminina pelo mercado de trabalho urbano. Por sua vez, dados relacionados à participação dos homens, exceto por um ligeiro aumento entre 2010 e 2013, demonstram que ela é mais consistente com as mudanças estruturais globais experimentadas pela economia bangladeshiana, que registrou um declínio na contribuição do setor agrícola para a renda nacional, em contrapartida ao aumento dos setores da indústria e de serviços. 
Tabela 3. Participação no total de empregos de homens e de mulheres nos diferentes setores da economia de Bangladesh (\%) no período 2000-201712

\begin{tabular}{|l|c|c|c|c|c|c|}
\cline { 2 - 7 } \multicolumn{1}{c|}{} & $\mathbf{2 0 0 0}$ & $\mathbf{2 0 0 5}$ & $\mathbf{2 0 1 0}$ & $\mathbf{2 0 1 3}$ & $\mathbf{2 0 1 5}$ & $\mathbf{2 0 1 7}$ \\
\hline Agricultura & 51,3 & 48 & 47,5 & 45,1 & 42,7 & 40,6 \\
\hline Homens & 52,2 & 41,8 & 40,1 & 41,7 & 34 & 32,2 \\
\hline Mulheres & 47,6 & 68,1 & 64,8 & 53,5 & 63,1 & 59,7 \\
\hline Indústria & $\mathbf{1 3 , 1}$ & $\mathbf{1 4 , 5}$ & $\mathbf{1 7 , 7}$ & $\mathbf{2 0 , 8}$ & $\mathbf{2 0 , 5}$ & $\mathbf{2 0 , 4}$ \\
\hline Homens & 11,3 & 15,1 & 19,6 & 19,6 & 22,3 & 22 \\
\hline Mulheres & 20 & 12,5 & 13,3 & 23,7 & 16,1 & 16,8 \\
\hline Manufacturas & $\mathbf{9 , 5}$ & $\mathbf{1 1}$ & $\mathbf{1 2 , 4}$ & $\mathbf{1 6 , 4}$ & $\mathbf{1 4 , 4}$ & $\mathbf{1 4 , 4}$ \\
\hline Homens & $\mathbf{7 , 4}$ & 10,8 & 12,7 & 13,9 & 14,2 & 14 \\
\hline Mulheres & 17,9 & 11,5 & 11,7 & 22,5 & 14,9 & 15,4 \\
\hline Serviços & $\mathbf{3 5 , 6}$ & $\mathbf{3 7 , 4}$ & $\mathbf{3 5 , 3}$ & $\mathbf{3 4 , 1}$ & $\mathbf{3 6 , 9}$ & $\mathbf{3 9}$ \\
\hline Homens & 36,4 & 43 & 41,1 & 38,7 & 43,7 & 45,8 \\
\hline Mulheres & 32,2 & 19,3 & 21,8 & 22,8 & 20,8 & 23,5 \\
\hline
\end{tabular}

Fonte: Labour Force Surveys (LFS) do Bangladesh Bureau of Statistics (BBS).

Segundo Raihan e Bidisha (2018), esse processo pode ser explicado, primeiro, devido à migração interna: os homens migram cada vez mais para as áreas urbanas e conseguem empregos no setor de manufaturas e de serviços, ao passo que as mulheres ficam responsáveis pelos cuidados com a propriedade e com a família, ou seja, pelo trabalho não remunerado. Com efeito, houve pequenas mudanças qualitativas para a força de trabalho feminina no decorrer das últimas duas décadas: cerca de um terço das mulheres empregadas ainda estão envolvidas em atividades não remuneradas. Segundo, frente ao baixo nível médio de capacitação técnica das mulheres, elas normalmente são mais afetadas pela automação dos processos produtivos fabris do que suas contrapartes masculinas. Das 30 fábricas $^{13}$ onde os autores fizeram entrevistas em 2017, com exceção das indústrias

\footnotetext{
122017 é o último ano em que esses dados estão disponíveis. O setor de manufaturas é um subsetor da indústria.

13 De diversas atividades: processamento de alimentos e agronegócio, couro, vestuário, madeira e móveis, produtos químicos e farmacêuticos, máquinas e equipamentos, serviços de transportes, de tecnologia da informação, varejo, etc.
} 
de vestuário, todas as demais tinham menos de $50 \%$ de mulheres no seu quadro de funcionários.

Para explicar a razão da pequena participação feminina na força de trabalho de Bangladesh, Solotaroff et al. (2019) se pautam no fato de que, ao contrário das mulheres que trabalham nas zonas rurais, o trabalho no meio urbano exige que elas fiquem mais tempo fora de casa, o que é mais provável que resulte em desaprovação familiar. A mesma investigação mostrou que em 2016 as mulheres habitantes das cidades de Bangladesh passavam cerca de seis horas em média por dia realizando tarefas domésticas e trabalho não remunerado, enquanto os homens urbanos dispendiam apenas uma hora por dia nessas atividades. Mesmo trabalhando pouco menos que os homens em média fora de casa ( 7 horas mulheres x 8,6 horas homens), elas ainda gastavam cerca de 3 horas por dia nas tarefas domésticas não remuneradas. Esses dados mostram que o trabalho doméstico pode representar um desafio ainda maior para as mulheres urbanas do que para as mulheres rurais no que toca à conciliação de atividades pagas e não remuneradas. Como explicado pela abordagem comércio e gênero, o conceito de que elas "contribuem para as famílias" em Bangladesh é ditado por normas sociais ligadas a gênero, que afetam a percepção das pessoas sobre as atividades que devem ser feitas por homens e por mulheres. As raízes conservadoras e patriarcais ligadas à religião muçulmana de Bangladesh reforçam a posição de pouca autonomia das mulheres na sociedade. O casamento precoce e o cuidado com o lar são elementos comuns na maioria das famílias bangladeshianas (Habib, 2014). Outro aspecto referente ao papel tradicional da mulher nesse país é o dote, que é uma quantia paga em dinheiro ou na forma de presentes dada pela família da noiva para o noivo. Nas áreas rurais, tal prática ainda é comum, e até hoje implica em que a mulher seja vista como um peso para a família, sobretudo para as mais pobres, porque muitas vezes não têm como pagá-lo.

O setor de vestuário de Bangladesh apresentou, em 2018, um dos salários mínimos mais baixos do mundo no setor de vestuário (figura 5). 


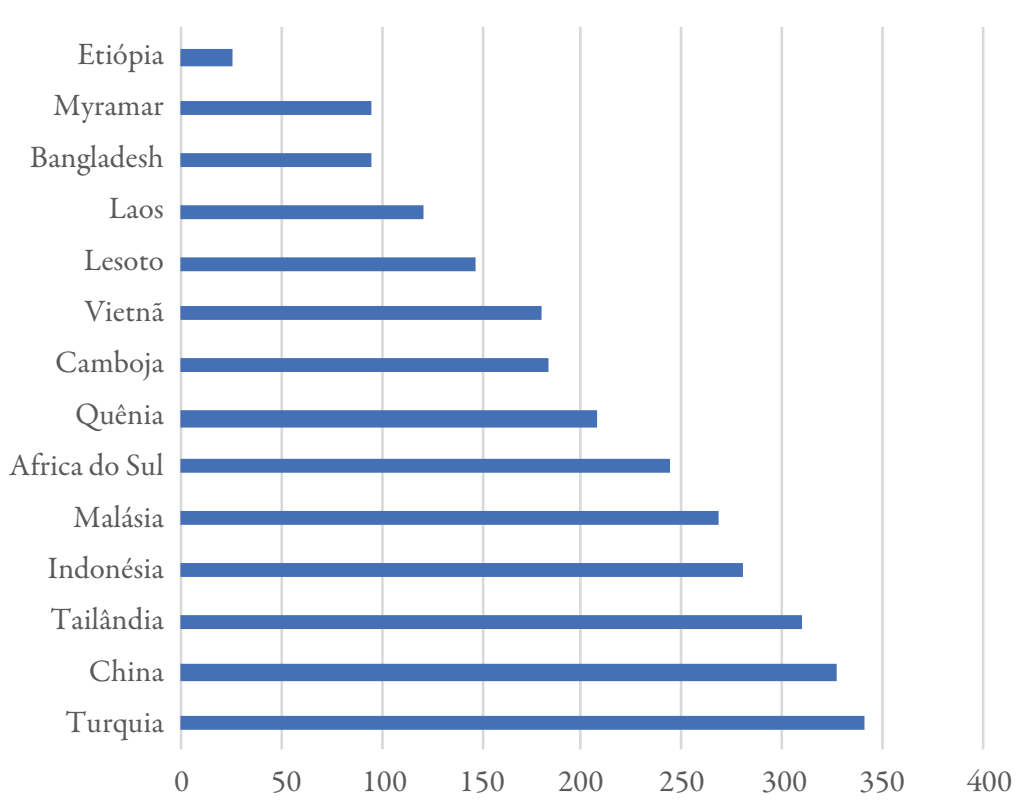

Figura 5. Salários mínimos mensais na indústria de vestuário (2018, em US\$, países selecionados) - 8 horas diárias de trabalho

Fonte: NYU Stern Center for Business and Human Rights/Statista

Há mais evidências que apontam que as consequências da liberalização comercial e de outras reformas econômicas pró-mercado sobre a economia de Bangladesh foram diferentes para homens e mulheres. Haque et al. (2015) argumentam que o espaço de negociação de trabalhadores da indústria de vestuário bangladeshiana com seus grandes clientes estrangeiros diminuiu nos últimos anos em razão do grande número de produtores de bens similares, constrangendo os empresários de Bangladesh a diminuírem seus custos de produção. À medida que outros polos especializados na produção de vestuário entraram na competição internacional, tiveram que enfrentar os mesmos desafios de produzir mais, com mais qualidade, a custos cada vez menores e em menos tempo. Os mesmos autores chamam a atenção para o fato de que, se por um lado, o "efeito-ameaça" implicou em mais pressão sobre custos unitários, para que os fornecedores se tornassem competitivos, criando resistências à melhoria dos salários e condições de trabalho e, por outro, a expansão da demanda mundial 
por roupas de menor preço e uma mudança da percepção da sociedade internacional acerca da forma como o vestuário é produzido constrangeram os empresários a garantir melhores condições de trabalho, permitindo, inclusive, que o nível de emprego se expandisse por um longo período, mesmo depois tendo tendência de queda. Por isso, os ganhos salariais médios das mulheres em Bangladesh foram relativamente pequenos e inferiores aos dos homens.

Nessa mesma linha, outros trabalhos econométricos apontaram que as diferenças salariais entre homens e mulheres têm diminuído no país, mas ainda variam entre 20 e $50 \%$ no setor de vestuário, sendo que uma das principais razões para essa discrepância é o menor nível da capacitação feminina média frente à masculina, mesmo depois da adoção de políticas públicas nos anos 1990 voltadas a incluir quase a totalidade de meninas de Bangladesh na escola (Ahmed \& Maitra, 2015). Os resultados da pesquisa, cuja amostra de funcionários em tempo integral entre 2005 e 2009 registradas no Labor Force Survey foi decomposta em categorias de renda, indicaram que as diferenças salariais são maiores na extremidade inferior da distribuição, ou seja, na proporção menos qualificada e mais vulnerável da população. Como significativa proporção de trabalhadores mal remunerados na parte inferior da distribuição em Bangladesh é de mulheres, a autora argumenta que elas enfrentam maior discriminação na base da distribuição salarial do mercado de trabalho do que no topo dela, a despeito dos esforços dos governos locais para ampliar a educação e o treinamento para a mão de obra feminina. As evidências apresentadas sugerem que, embora o acesso à educação e à formação relacionada ao trabalho seja fundamental para dar às mulheres salários mais competitivos - e há evidências de uma amostra de mais de 57 mil indivíduos de que isso aconteceu no período considerado -, elas ainda recebem salários inferiores aos homens, sendo maior a discriminação nas categorias nas quais os salários são mais baixos. A razão para isso está mais ligada à discriminação contra as mulheres na sociedade e no mercado de trabalho, e não a sua capacitação ou escolaridade. 
Dados coletados de 80 mil trabalhadores de 70 das maiores fábricas de vestuário de Bangladesh e analisados durante 13 meses por Menzel e Woodruff (2019) revelaram que os homens ascendem mais na carreira que as mulheres, e, por isso, os salários deles crescem em torno de $60-70 \%$ mais rápido nos primeiros estágios da vida profissional do que os delas. A mesma análise apontou que as mulheres ganham menos mesmo quando estão na mesma função que os homens e que somente $1 / 3$ das diferenças salariais entre eles no país podem ser explicadas por discrepâncias de capacitação, ou seja, há, na verdade, discriminação social em relação às mulheres.

Ainda nos anos 1990, Paul-Majumder e Begum (2000) fizeram entrevistas com mais de 1000 trabalhadores durante vários anos e comprovaram que a maioria das fábricas de vestuário não garantia um ambiente de trabalho minimamente satisfatório. As trabalhadoras raramente possuíam contrato e, mesmo assim, não protestavam porque temiam perder o emprego. Além de violar as regras governamentais de salário mínimo, a pesquisa também atestou que na maioria das fábricas as trabalhadoras eram vítimas de assédio físico, sexual e verbal, o que afetava o seu estado de saúde. Violações às leis por excesso de horas de trabalho eram constantes porque o desempenho das exportações de Bangladesh dependia muito mais do volume exportado do que do preço unitário do produto.

\section{Conclusão}

A aplicação de uma perspectiva analítica não convencional neste artigo, que relaciona comércio internacional e gênero, a um estudo de caso da reestruturação econômica de um PMD, como Bangladesh, teve como fim identificar os impactos da liberalização comercial e da especialização produtiva sobre a mão de obra feminina do país desde os anos 1980. Essa abordagem prima por um olhar crítico aos pressupostos da economia neoclássica, os quais admitem que o mercado é eficiente, sem levar em conta os distintos papeis ligados ao gênero, para explicar as experiências de mulheres em vários países do mundo. 
Tendo em vista que fatores externos, na trilha das transformações derivadas da globalização e da integração dos mercados, como a busca de grandes empresas globais por vantagens comparativas de produção em países pouco industrializados e desenvolvidos, assim como internos, como as decisões políticas de abertura econômica no escopo das reformas neoliberais realizadas por governos bangladeshianos, e o grande contingente de mão de obra feminina barata disponível, ficou evidenciado como e porque Bangladesh se tornou um dos maiores produtores e exportadores de peças de vestuário do mundo e qual foi a participação feminina nesse processo.

Por um lado, o bom desempenho do setor de vestuário, ligado à "feminização" da força de trabalho via instrumentalização das desigualdades de gênero presentes na sociedade bangladeshiana, repercutiu positivamente no fortalecimento da indústria manufatureira, no crescimento econômico e no PIB per capita, na ampliação das exportações e na maior empregabilidade da mão de obra feminina em serviços urbanos no país. Por outro lado, por razões estruturais ligadas à economia e à sociedade e às decisões políticas industrial e comercial de vários governos, a participação das mulheres no mercado de trabalho, incluindo o emprego nas indústrias, continuou inferior aos homens e às mulheres de outros países, assim como a sua remuneração e as oportunidades de qualificação e ascensão profissional. Em Bangladesh, persistem desigualdades horizontais e verticais de gênero. Especificamente no setor de vestuário - uma exceção, uma vez que a participação é majoritariamente feminina -, a despeito do maior número de contratações e do ligeiro aumento do nível de salários, há evidências de que ainda há importantes limitações do poder de barganha da força de trabalho feminina, prevalecem más condições e jornadas exaustivas de trabalho e a mulher continua sujeita a diversos tipos de violência. Ficou patente que as oportunidades de ascensão profissional e social das mulheres não ocorreu na mesma proporção e ritmo da contratação pela indústria de vestuário, da criação de comércio e do progresso econômico do país. Também não houve significativo progresso tecnológico, diversificação produtiva e desenvolvimento econômico em Bangladesh à altura do ritmo das taxas de crescimento do PIB do país. Ao contrário, a especialização 
produtiva deixou a sua economia ainda mais dependente da produção e exportação de um só produto, isto é, o país se inseriu nas CGV do setor, na esteira das escolhas que fez para se integrar ao capitalismo global, mas, isso não reverberou no seu desenvolvimento econômico e na igualdade de gênero.

Em abril de 2013, Bangladesh chamou a atenção do mundo quando uma fábrica na Rana Plaza, localizada na periferia de Dhaka, veio abaixo. Mais de 1.100 trabalhadores morreram e 2.500 ficaram feridos, em sua maioria, mulheres. Infelizmente, esse episódio não foi o primeiro nem será o último. Desde então, formalmente, há maiores exigências de segurança e respeito aos direitos humanos do que no passado, e as mulheres vêm conseguindo se organizar mais para exigir melhores condições de trabalho, muitas marcas globais europeias estão impondo maior segurança nos locais de trabalho para continuar importando de Bangladesh, mas, na prática, não há fiscalização suficiente ou mesmo interesse de que isso seja feito, nem por parte das grandes marcas estrangeiras, tampouco pelos donos das fábricas ou do governo.

\section{Referências}

Adnan, A., Rakib, A., \& Rahman, M. (2015). Export trend of Bangladesh: The dominance of ready-made garments industry. Research Journal of Economics, Business and Ict, 10(1), 25-3.

Ahmed, F. Z., Greenleaf, A., \& Sacks, A. (2014). The paradox of export growth in areas of weak governance: The case of the ready made garment sector in Bangladesh. World Development, 56, 258-271. https:// doi.org/10.1016/j.worlddev.2013.11.001.

Ahmed, S., \& Maitra, P. (2015). A distributional analysis of the gender wage gap in Bangladesh. The Journal of Development Studies, 51(11), 1444-1458. https://doi.org/10.1080/00220388.2015.1046444.

Akorsu, A. (2016). The feminization of labor. In N. A. Naples, R. C. Hoogland, M. Wickramasinghe \& A. W. C. Wong (Eds.), The wiley blackwell encyclopedia of gender and sexuality studies (pp. 1-3). Willey-Blackwell. https://doi.org/10.1002/9781118663219.wbegss027. 
Amsden, A. (1989). Asia's next giant: South Korea and late industrialization. Oxford University.

Bangladesh Knitwear Manufacturers and Exporters Association, BKMA. (2018). Apparel Statistics of Bangladesh FY 2016-2017. Ministry of Finance.

Barrientos, S. (2007). Global production systems and decent work. International Labour Organization Working Paper, 77, 1-35.

Benería, L., Berik, G., \& Floro, M. S. (2015). Gender, development and globalization: economics as if all people mattered. Routledge.

Benería, L., Floro, M. F., Grown, K., \& MacDonald, M. (2000). Introduction: Globalization and gender, Feminist Economics, 6(3), 7-18. 10.1080/135457000750020100.

Butt, A., Remme, J., Rost, L., \& Koissy-Kpein, S. (2018). Exploring the need for gender-equitable fiscal policies for a human economy: Evidences from Uganda and Zinbabwe. Oxfam Research Reports, 1-64.

Caves, R. E. (2003). The Multinational Enterprise as an Economic Organization. In J. Frieden, \& D. Lake (Eds.), International Political Economy: Perspectives on Global Power and Wealth (pp. 145-155). Routledge.

Charmes, J. (2019). The Unpaid Care Work and the Labour Market. An analysis of time use data based on the latest World Compilation of Time-use Surveys. International Labour Office.

Chesnais, F. (1996). A mundialização do capital. Xamã.

Dicken, P. (2011). Mapping the changing countours of the world economy. Sage Publications.

Evans, P. B. (1995). Embedded autonomy: States and industrial transformation. Princenton University Press.

Farole, T. \& Cho, Y. (2017 2018). Jobs diagnostic Bangladesh main report. World Bank.

Floro, M. S., \& Willoughby, J. (2016). Feminist economics and the analysis of the global economy: The challenge that awaits us. The Fletcher Forum of World Affairs, 40(2), 15-27.

Fontana, M. (2003). The gender effects of trade liberalization in developing countries: A review of the literature. Discussion Papers in Economics, 101,1-29.

Freeman, C. (2000). High tech and high heels in the global economy: Women, work, and pink collar identities in the caribbean. Duke University Press. 
Gatti, D. D., Gallegati, M., Greenwald, B. C., Russo, A., \& Stiglitz, J. E. (2012). Mobility constraints, productivity trends and extended crises. Journal of Economic Behavior \& Organization, 83, 375-383. https://doi. org/10.1016/j.jebo.2012.03.011

Ghosh, J. (2002). Globalization, export-oriented employment for women, and social policy: A case study of India. United Nations Research Institute for Social Development.

Goldin, C. (2014). A grand gender convergence: Its last chapter. American Economic Review, 104(4), 1091-1119. 10.1257/aer.104.4.1091.

Gomes-Casseres, B. (1998). The alliance revolution: The new shape of business rivalry. Harvard University Press.

Grossmann, G. M., \& Helpmann, E. (1991). Trade knowledge, spillovers and growth. NBER Working Paper, 3485, 517-526.

Guttmann, R. (1998). As mutações do capital financeiro. In F. Chesnais (Ed.), A mundialização financeira: gênese, custos e riscos. Xamã.

Habib, A. (2014). Women in the garment industry of Bangladesh: A paradox of women empowerment and transformation of structural violence (Master Thesis), Artic University of Norway.

Haque, E., Rana, S., \& Abedin, Z. (2015). Assessing the quality of work life of garment workers in Bangladesh: A study on garment industries in Dhaka city. Global Journal of Management and Business Research, 15(3), 63-74.

Harvey, D. (1992). Condição pós-moderna: uma pesquisa sobre as origens da mudança cultural. Loyola.

International Labour Organization, ILO. (2018). Care work and care jobs for the future of decent work. International Labour Office Publishing.

International Monetary Fund, IMF. (2019). IMF world economic outlook. IMF Publishing.

Kabeer, N. (2012). Women's economic empowerment and inclusive growth: Labour markets and enterprise development. DFID/IDRC Working Paper, 1, 1-65.

Krueger, A. (1998). Why trade liberalization is good for growth. Economic Journal, 108(450),1513-1522. https://doi.org/10.1111/14680297.00358.

Larraín, F., \& Vergara, R. (1998). Income distribution, investment and growth. In Solimano, A. (Ed.), Social inequality values, growth and the state (pp. 120-139). University of Michigan Press. 
Menzel, A., \& Woodruff, C. (2019). Gender gaps and worker mobility: Evidence from the garment industry in Bangladesh. NEBR Working Paper, 25982, 1-55.

Panitch, L., \& Gindin, S. (2012). The making of global capitalism: The political economy of american empire. Verso.

Paul-Majumber, P., \& Begum, A. (2000). The gender imbalances in the export oriented garment industry in Bangladesh. Gender and Developing Working Paper Series, (12), 1-40.

Pepermans, A. (2019). China as a textile giant preserving its leading position in the world, and what it means for the EU. Taiwanese Journal of Political Science, 80, 63-108. 10.6166/TJPS.201906 (80).0004.

Rahman, M., \& Sayeda, T. (2016). the effect of integration with global apparel value chain: The case of Bangladesh apparel industry. South Asia Economic Journal, 17(2), 1-23. https://doi.org/10.1177/1391561416650587.

Raihan, S., \& Bidisha, S. (2018). A research paper on economic dialogue on inclusive growth in Bangladesh. ODI the Asia Foundation, the UK Government.

Raihan, S. (2008). Trade liberalization and poverty in Bangladesh. Macao Regional Knowledge Hub Working Papers, (15), 1-16.

Razavi, S., \& Hassim, S. (2006). Gender and social policy in global context: Uncovering the gender structure of "the Social”. In S. Razavi \& S. Hassim (Eds.), Gender and social policy in a global context (pp. 1-39). Palgrave Macmillan.

Rodrick, D. (2004). Industrial policy for the twentieth century. NEBER Discussion Paper, 2738, 1-56.

Rodrick, D. (2018). New technologies, global value chains and the developing economies. Pathways for Prosperity Commission Background Paper Series, 1, 1-27.

Rodriguez, F., \& Rodrick, D. (1999). Trade policy and economic growth: A skeptic's guide to the cross-national evidence. NBER/Macroeconomics Annual, 15(1): 261-325. https://doi.org/10.3386/w7081.

Seguino, S., \& Grown, C. (2006). Feminist-kaleckian macroeconomic policy for developing countries. The Levy Economics Institute, Working Paper, 446, 1-30.

Seguino, S. (2002). Gender, quality of life and growth in Asia from 1970 to 1990. The Pacific Review, 15(2), 245-277. https://doi.org/10.1080/ 09512740210131059. 
Solotaroff, J. L., Aphichocke, K., Lonnberg, T., Snighda, A., Pande, R. P., \& Pande, F. J. (2019). Voices to choices: Bangladesh's journey in women's economic empowerment. International development in focus. World Bank.

Standing, G. (1999). Global feminization through flexible labor: A theme revisited. World Development, 27(3): 583-602.

Stiglitz, J. (2002). A globalização e seus maleficios: a promessa não-cumprida de benefícios globais. Futura.

The Organization for Economic Cooperation and Development, OECD. (2019). Enabling women's economic empowerment. New approaches to unpaid care work in developing countries. OECD Publishing.

The Organization for Economic Cooperation and Development, OECD. (2019). Enabling women's economic empowerment. New approaches to unpaid care work in developing countries. OECD Publishing.

Tran-nguyen, A., \& Zampetti, A. B. (2004). Trade and gender: Opportunities and challenges for developing countries. UNCTAD.

United Nations Children's Fund, UNICEF. (2017). Glossary of terms and concepts. UNICEF regional office for South Asia.

United Nations Conference on Trade and Development, UNCTAD. (2014). Trade and gender: Unfolding the links. UNCTAD.

van Staveren, I. (2005). Feminist economics: Setting out the parameters. In C. Bauhardt \& G. Caglar (Eds.), Feministische kritik der politischen ökonomie (pp. 18-48). VS Verlag für Sozialwissenschaften.

van Staveren, I. (2013). An exploratory cross-country analysis of gendered institutions. Journal of International Development, 25(1), 108-121. $10.1002 /$ jid.1850.

Wade, R. (1990). Governing the market: Economic theory and the role of government in east asian industrialization. Princeton University Press.

Wang, L., \& Klugman, J. (2020). How women have fared in the labour market with China's rise as a global economic power. Asia \& Pacific Policy Studies, 7(1), 43-64. https://doi.org/10.1002/app5.293.

World Bank. (2012). World development report: Gender equity and development. World Bank Publishing.

World Bank. (2019). The world bank in Bangladesh: Overview. World Bank Publishing.

World Trade Organization, WTO. (2019). World trade statistical review. WTO. 
40 / Patricia Nasser de Carvalho

Yunus, M., \& Yagamata, T. (2012). The garment industry in Bangladesh. In T. Fukunishi (Ed.), Dynamics of the garment industry in low-income countries: Experience of Asia and Africa (pp. 1-26). IDE-JETRO. 